\title{
Shaping the contours of fractured landscapes: Extending the layering of an information perspective on refugee resettlement.
}

\author{
Keywords: fractured landscapes, remaking, refugees, information practices, information \\ literacy, social capital, technology
}

\begin{abstract}
Refugee experience of resettlement into a third country is problematised by posing the question, what happens when an established information landscape fractures? Themes of disjuncture, intensification and liminality that have emerged from the author's research are described, using social theories as the analytical lens to shape the contours of fracture. Two other questions are posed How is digital space implicated in rebuilding information landscapes that have become fractured? and; What is the role of technology in enabling or constraining the conditions for remaking place?
\end{abstract}

\section{Introduction}

An unacknowledged impact of forced migration is its potential to fracture and untether people from existing information landscapes (Lloyd, 2006) that have been anchored in established routines, ways of knowing and know-how. Forced migration is a complex social and cultural process that differs from other forms of migration, such as economic or social migration, because it is not voluntary, planned, or controlled to any large extent by those who experience it. The imperative to go on features in stories about transition and resettlement, such as wanting to get back to normal, start a new life, create and take up new opportunities, be safe, or become and participate as a citizen of a destination country.

A significant theme threaded through these narratives is the role of the digital space, represented as an immanent and seamless presence, and, by implication, of the technologies that afford access to that space. In the emerging corpus of library and information science literature that investigates refugees and their information experiences and needs, growing attention has been paid to identifying technologies that scaffold access to information resources, focusing not only on what enables but also on what disrupts and constrains. There has been less focus, however, on exploring and understanding the implications of this access in relation to rebuilding landscapes fractured through forced migration. The online world is viewed as a social space enabled by technology and acting as a site for interaction, communication and networking, and as a place to find, create and disseminate information (Lloyd, et $a l ., 2013)$. It is also the place to say "I am here, I am alive, and this is my story". In digital space people actively negotiate their pathways; it represents, therefore, an important social ground where responses and solutions to resettlement and integration are played out in many different ways by numerous actors.

The first section of this article continues the conceptual layering started by the author (Lloyd, 2014) to scaffold forced migration from an information studies perspective. When problematised from this perspective, forced migration focuses on information as a core resource essential for successful resettlement and integration. This perspective problematises what enables or constrains the experience, considering themes such as precarity and resilience in the context of the lived experience, and represents a significant category for deep qualitative analysis. Secondly, the article introduces theories and concepts that have been employed in an account of the lived experience of the fracturing and remaking of information landscapes fundamental to successful resettlement. Finally, the article considers how technology is implicated in remaking fractured landscapes. To guide this work, three questions are posed: What happens when an information landscape fractures?; How is digital space implicated in rebuilding information landscapes that have become fractured? and; What is the role of technology in enabling or constraining the conditions for remaking place? 


\subsection{Overview of studies}

The conception of fracture has emerged from an ongoing research program that focuses on understanding refugee experiences of resettlement into a third country from an information perspective. Data has been collected from several studies, each with a different focus, such as experiences of resettlement, health information, refugee youth and learning, Syrian resettlement experiences in Sweden, which the author and her colleagues have reported in the literature (i.e. Setters study, Lloyd, et al., 2013; refugee health information, Lloyd, 2014; KaLieds-Knowing and Learning in everyday spaces Lloyd \& Wilkinson, 2019; SpIRit- Supporting Refugees in Transition Lloyd, Pilerot \& Hultgren, 2017). Each of the studies was framed by social cultural approaches, employed qualitative methods, and utilised in-depth interviews, photo-voice techniques and focus groups. The range of qualitative methods employed enabled participants to describe their experiences in depth and in their own terms and aimed to provide thick descriptions (Geertz, 1994) grounded in their reality of their experience. The use of photo-voice method enabled participants to express their thoughts and experiences visually when language and/or literacy were limited (Lloyd 2014, Lloyd \& Wilkinson 2019). Participants in these studies were from South Sudan, Syria, and Afghanistan; all had been granted refugee status and were now resettled in a receiving country (either Australia or Sweden).

The overarching goal of the studies and the continuing research program has been to develop an understanding of the complexity and experiences of refugees as they become immersed with the process of resettlement into a receiving country. The studies analysed their experiences from an information perspective, investigating not only tangible elements, such as preferred sources, and information literacy practices, but also the inherent information experiences associated with being forced to leave familiar information environments and having to reconnect and re-establish in the unfamiliar information environments of a receiving country. The concept of information resilience emerged from these studies, and is described as the application of information practices and information resources to enable people to bounce back from difficult situations (Lloyd, 2015).

\subsubsection{Forced Migration}

Forced migration is made complex by issues such as status, the conditions that influence movement and context. There is much debate about where research into forced migration and resettlement should be positioned (Castels \& Miller, 2009). Van Hear (2012) suggests that forced migration studies should be located within broader discussions about migration, but, at the same time, the topic should also be viewed as representing a specific line of enquiry that is subject to definitions and terminology relating to who is classified and defined as a refugee and who as a migrant. Areas for investigation include the conditions that induce flight, but also familial, professional, employment, and educational reasons for dispersal and the capacity for mobilisation, which, according to Van Hear (2012, p.11), is dependent upon "mobilization of resources or different endowments of various forms of capital (human, social, political, cultural, symbolic)".

This yiew has implications for library and information science researchers, for whom information experience, sources, practices, and behaviours are at the core of their enquiry. In the analysis presented here, the conceptualisation draws from social theory and from research conducted in information studies to present a more complex view of resettlement as a consequence of forced migration. Over the past decade information-focused research into migration has begun to emerge that distinguishes between migrants who have had their refugee status confirmed and those who are general or economic migrants, and between resettlement contexts(Lloyd, 2017). This has allowed for deeper and more nuanced analysis which recognises that, while at some level migrants and refugees may have similar information needs, it is critical that generalisations are not made about the two groups, and identifies and acknowledges the vital role of context and conditions in shaping the complex information environments that displacement creates. 


\subsubsection{Refugees and migrants}

The United Nations High Commissioner for Refugees stresses the importance of distinguishing between refugee and migrant designations. According to the UNHCR (2016), the terms refugee and migrant have different meanings, and using them interchangeably can lead to significant problems. Clarity in their usage has implications for research in which refugees or migrants participate and their experiences are explored. The nature and circumstances of each group's experience of migration, transition and resettlement complicate how researchers understand their experience and the decisions researchers make about what information aspect or dimension or information-related activity to research (King 2013).

According to the UNHCR, refugees are people with a well-founded fear of persecution, because of their race, politics, religion, sexuality, nationality or cultural affiliation, who are fleeing armed conflict or persecution and crossing international borders (UNHCR, 2016). Significantly, not all displaced people seek resettlement in other countries. Some people may prefer to move to neighbouring countries and stay close to home, with the hope of returning, while others may choose to stay in their country, but away from their homes (UNHCR, 2016).

Migrants, often distinguished as economic or social, move voluntarily and face no impediment or danger if they return to their homelands. For most of these people, their migration is driven by economic or social factors (family reunion, employment, education or other opportunities) (Castles and Miller, 2009, UNHCR, 2016). Economic migrants are often better organised, have complete documentation, may have made prior arrangements for their resettlement process, and often have family and/or economic resources to support their transition (Khoir, Du \& Koronios, 2015). Because migrants are able to control their movements and their social, economic, political, and cultural realities, their information landscapes will be less fractured than those of refugees. Both Lloyd (2017) and Fisher (2018) have noted that, while people have common experiences in relation to their information needs, people experiencing forced migration and resettlement may have difficulty in accessing information to meet their requirements, or may have difficulty with language, or may experience social, financial, material factors that complicate their movement and resettlement.

\subsubsection{Context of resettlement}

The context for the research described here is refugee resettlement, described by the UNHCR as the 'selection and transfer of refugees ftom a state in which they have sought protection to a third State which has agreed to admit them- as refugees- with permanent residence status" ( UNHCR, 2011, p. 9). Resettlement is considered one of three durable solutions by the UNHCR. The other two solutions are referred to as local integration, in which refugees are resettled in the country of refuge or granted asylum prior to acceptance by a third State and voluntary repatriation to a country of origin (UNHCR, 2011). Resettlement is not codified within international law, but remains at the discretion of countries that acceptrefugees for resettlement (UNHCR, 2018). Resettlement occurs when both repatriation and local infegration are unfeasible or safe, or when refugees have specific needs that cannot be met by the country of refuge for social or economic reasons (UNHCR, 2002, p. 4). Resettlement countries are responsible for the reception of refugees, provision of accommodation on their arrival, language training and cultural orientation, ongoing settlement and integration activities, naturalisation, and citizenship (UNHCR, 2011).

All of the designations and definitions surrounding the process of resettlement, whether local integration or resettlement in a third State, have an impact on the lived experiences of refugees as they resettle. This in turn influences the reshaping of their information landscapes that are disrupted when they are forced to leave their established lives and physical social networks, and the routines of their information practices and behaviours. Following their displacement people may attempt to recreate their networks, to maintain contact and reaffirm their identity, and to access new forms of information essential for travel, transition and resettlement. Consequently, smartphones become an essential tool in 
creating digital landscapes (Gillespie et.al, 2016; Alencar, 2018). While the information needs of refugees and migrants may be thought to be similar, it is important to note that the process of migration, whether forced or voluntary, is subject to politics and policy, which influence the type and scope of the information they require, the complexity of their information practices, information seeking and access and use decisions, and, consequently, individual agency.

Accordingly, the context, circumstances, and consequences of displacement or migration will influence research practice and highlight decisions about methodological and ethical aspects of research, including what to focus on, the methods selected, and the length of time spent in fieldwork. In addition, research that focuses on displacement also acknowledges and accounts for the position of the researcher, as well as issues relevant to the nature of displacement, including research fatigue which can affect refugee and asylum seekers as research into their movement and experience increases. For example, Maitland et al. (2015 and 2016), Wall, Otis Campbell \& Janbek (2017), and Fisher et al. (2017) have reported ethnographic research focusing on displaced persons located primarily in Za'atari refugee camp in Jordan, with return visits to gather and collect data. The research of Lloyd and colleagues ( identified in 1.2) has focused on a program of smaller in-depth studies in order to understand better the lived experiences of refugees in the process of transitioning and resettling into a third country, and the nature of social inclusion and resilience. In undertaking transition and resettlement studies, emphasis has been placed on acknowledging the researchers' positionality and ensuring that participants' voices are heard.

To summarise, awareness of nomenclature distinctions and the context of study is particularly important for library and information science researchers pursuing an interest in refugees' information experiences and information practices, because the nature of their experiences, information needs, and modes of access to information may differ from, and be less stable than, those of migrants who have the ability to control their departures. The inability of refugees to control their movement or decisionmaking about that movement can lead to the fracturing of their information landscapes.

\subsubsection{Studies of refugee information practice and use}

An increasing number of research studies that focus on refugees' experiences of third country resettlement, ICT use, and social media to support them in dealing with the demands of forced migration and with social inclusion and marginalisation issues have been reported in the literature of library and information science (Allard \& Caidi, 2018; Díaz Andrade \& Doolin, 2019; Le Louvier \& Innocenti, 2019; Martzoukou \& Burnett, 2018; Oduntan \& Ruthven, 2019). A review of research conducted by Caidi, Allard and Quirke (2010) focused on information practices of immigrants and refugees. It foregrounded the research area and described the range of information needs, approaches to information seeking, and research methods being adopted. Allard and Caidi (2018) continue to contribute this area and have reported on translocal meaning-making, describing the activities and outcomes of the information practices of newcomers as they participate across local and global social networks. In a 2014 review within the library and information science field, Quirke (2014, p. 14) identified two strands of research as research-practitioner research (library and information science); and immigrant human information behaviour (HIB). According to Quirke, much of the research up to 2014 fell into the library and information science category of design and delivery of programmes, thus making them "of limited use in understanding the HIB of immigrants and refugees more generally" (Quirke, 2014, p. 15). The second category, immigrant HIB (Quirke, 2014, p. 15), highlights studies that are either exploratory and qualitative in nature, focused on specific groups, or framed by a diverse assortment of theoretical and conceptual devices and therefore lacking focused or cohesive structure. Quirke identified a range of models, such as gatekeeper models, information seeking and needs models, theoretical approaches such as phenomenology (Dali, 2010), practice theoretical approaches (Lloyd et al., 2013) and conceptual approaches such as social capital (Audunson et al., 2011) and information grounds (Fisher et al., 2004). 
Mobile technology and information and communication technologies (ICTs) have been a significant focus for numerous researchers working with refugees in camps along the border between Syria and Jordan. Fisher and colleagues have undertaken research with Syrian refugees (Fisher, 2016; Fisher $e t$ al., 2016; Maitland et al., 2015) which has focused primarily on mobile devices and internet usage by refugees in Za'atari camp. Fisher and colleagues have reported on other research that focuses on the role of food (Fisher et al., 2017). Other research emerging from Za'atari include work by conducted Wall, Otis Campbell, and Janbek (2017), who consider how mobile technology is used to help Syrian refugees living in Jordan. They suggest that, while mobile technology has been strongly associated with finding, keeping and maintaining social networks, it can also be viewed from a political perspective, and associated with finding and disseminating news, creating global images to reinforce views and supplement professional news of events in Syria. Wall, Otis Campbell and Janbek (2017, p. 253) point out that agency empowered through mobile phone usage can also be seen as fragile and vulnerable to issues such as accessing a network, finding suitable SIM cards, and government surveillance.

A broad body of research focused on the enablement and implications of ICTs and social media has begun to highlight the seamless enmeshment of digital information and technologies into the lives and information landscapes of displaced people. Drawing from Appadurai's acknowledgement of the increasing importance of ICTs in the "process of maintaining and creating diaspora" (Appadurai, 1996, p. 1734), Srinivasan and Pyati (2007) called for a reframing of placed-based research to acknowledge the importance of the globalized diasporic to the shaping of resettled refugees' and immigrants' information landscapes. Research has been undertaken by Dekker, Engbersen, Klaver and Vonk (2018), who investigated Syrian refugees' use of social media in decision making, highlighting the positive aspects (timeliness and experiential nature of information that could be accessed), while also indicating structural issues related to network reliability. Gillespie, Osserian and Chessman (2018) have approached issues related to the affordances of ICTs in terms of planning, navigation and documentation, by drawing from infrastructural and affordance-based approaches.

Refugee relationships with social media and ICT use has been explored by Alencar (2018) who reports on the relevance of social media networking sites for refugees in the acquisition of language, cultural competencies, and building, bonding and bridging capital, necessary for resettlement and rebuilding disrupted lives. Social media are also identified for their role in enabling and maintaining connections with family in other countries. Alencar also notes the importance of social media in connecting refugees with people in the receiving country which helps with their integration. Díaz Andrade and Doolin's study (2019) identifies the importance of ICTs in reaffirming the identity of refugees which is often challenged in the process of forced migration and resettlement.

Social media use has also been associated with the affordance of ambient co-presence, described by Madianou (2016) as mediated co-presence afforded by social media which enable intense awareness of others and contribute to "doing family" when families are dispersed. Madianou (2016) recognises that, while this kind of social surveillance may be positive in maintaining cultural links, it can also be oppressive and lead to a suspicion of technology. Earlier analysis by Komito (2011) tied refugees' information experiences to social capital theory, which has been extended by other researchers (Lloyd et al., 2013; Vårheim, 2014). While most researchers view the positive aspects of social media in contributing to social inclusion, Komito (2011, p. 1075) also observes that the maintenance of cultural ties may have implications for the process of integration and participation in host societies.

Digital literacy has been identified by Gilhooly and Lee (2014) as playing a significant role in the resettlement process by facilitating co-ethnic friendship and connection to cultural groups, which helps rebuild ethnic solidarity. They argue that access to internet facilities help young people deal with social economic and education demands of resettlement. Lloyd and Wilkinson (2019) made similar findings in their study of learning and literacy outside formal schooling. 
Previous studies have highlighted the need for refugees to reconcile information practices from their previous lives with those of their new communities; the constraining effect this has on their transition has been raised (Allard, Mehra and Qayyum, 2007; Quirke, 2014). The connection between socioeconomic status, the digital divide, information poverty, and the capacity to become misinformed have also been explored (Lloyd et al., 2013; Yu, 2010). Studies have also been conducted in the information science field, which have focused on how perceived diminished competency (associated with language and comprehension) can influence how resettling refugees understand and navigate new information environments, suggesting that a wider range of formats can increase the risk of marginalisation and limit their capacity to rebuild social capital. This can, in turn, promote the creation of parallel societies, information poverty, and social exclusion (Caidi \& Allard, 2005) and impede information resilience (Lloyd, 2014), which ultimately has implications for civil society in terms of social inclusion, integration, and the rebuilding of social capital

\section{Influencing perspectives and theories: An information perspective.}

In the last ten years, refugee transition and resettlement has been discussed across many disciplines and from many different social, economic, physical and emotional perspectives. The fundamental perspective often missing from or not dealt with in detail in these discussions is the information perspective. Successful resettlement hinges, firstly, on the ability to recognise the social, material and embodied affordances of a context and its relevant settings; identifying what enables and constrains access to information; and operationalising the information practices that enable a person to become informed. These elements are necessary to redress the social and economic vulnerabilities that have an impact on information access and create the conditions for precarity (Butler, 2006; Banki, 2013) or information precarity (Wall, Otis Campbell \& Janbek, 2017). Secondly, inherent to the process of resettlement is the capacity to leverage social sites and their sources of information (resources) - not only those that are explicit and in textual form, but also those that comprise social and embodied (community and local) information. Finally, successful resettlement requires recognition of and access to the forms of social capital that will facilitate the markers and means of integration, namely employment, housing, the maintenance of physícal and mental health, and the educational participation (Strang \& Ager, 2010).

The ubiquitous nature of information means that it is a tricky task to view it as a core analytical category; it raises questions about boundaries and what constitutes information (as object, content, knowledge, data (Bates, 1999; Buckland, 1991; Furner, 2015)) and about the way we react to it or make meaning with it. In adopting an information perspective, Bates (1999, p. 1048) argued that we should follow the red thread of information, drawing attention to information and information-specific relationships and activities that scaffold enactment, and enable enactment in relation to the knowledges and practices of the setting. The red thread represents information that acts as an invisible link that ties people together in a 'social tapestry'(Bates, 1999, 1048) connecting practices together in a social site. As Bates (1999, p. 1048) suggested: "In comparison to other social and behavioural science fields, we are always looking for the red thread of information in the social texture of people's lives. When we study people, we do so with the purpose of understanding information creating, seeking and use".

While resettlement may be understood in terms of access to tangible and explicit forms of knowledge ("information as thing" (Buckland, 1991)) or in terms of the use of technology or data as thing (Furner, 2015), this understanding represents only half the story, because information is made available to us through our social relations, interactions, and corporeal experiences, which, together with epistemic modality, we draw from to compose our information landscapes (Lloyd, 2010).

To address the question of boundedness (or lack of boundedness) of the social and physical dimensions of information and to emphasise an information perspective, this article will draw from a generative 
proposition by Dourish, Brewer and Bell (2005) and reiterated by Dourish and Bell (2011), that information and knowledge should be viewed as a cultural category. From this view, everyday life can be understood in informational terms as being composed of different forms of information drawn from different sites of knowledge, which act to inform us and which shape and influence how information and the ability to become informed is experienced and understood by people enmeshed in settings. The concept of power resides within this conceptualisation, as shaping discourse and practice and thus creating the potential for precarity as refugees interact with new information environments and create new information landscapes. This approach also directs the researcher's gaze towards problematising how people become informed and, in that process, build, develop, and then anchor their information landscapes (Lloyd, 2006). From this view, being informed is predicated on being able to develop ways of knowing the practices and competencies required to work with information that is afforded through the social, material and technical mechanisms of a community, society or culture.

\subsection{Information landscapes and literacies of information}

The concept of information landscapes (Lloyd, 2006) reference how practices emerge and happen as people interact with larger information enviornments (for example, health, education, government agencies, migration agencies) and with other people, material objects and the embodied performances of a specific setting. Information landscapes are, firstly, spaces that reference the taken-for-granted and agreed modalities and sources of information that reflect enterprises and performances of people engaged in collective action (for example, learning to live in a new community, engaging with health, participating in education or work) (Lloyd, 2012). Secondly, information landscapes express individual agency (how we connect, or participate, how we seek information, the kinds of technology we use), as it is discursively materialised (Barad, 2007). To enter a new culture, society and its communities (workplaces, educational settings, health, etc.) and to access its resources, refugees have to learn about the cultural, material, economic, political and historical resources that shape the site of the social (Schatzki, 2002). They also have to engage with information practices such as information literacy that will provide them with the capacity to engage, access and evaluate information.

Information literacy practice is an example of an information practice. This practice represents the ways of knowing those modalities made available to people as they experience and learn to go on in a social site, hence the claim that information is both "practised and culturally bound" and thus representing a cultural category (Dourish, Brewer \& Bell, 2005). In daily life people interact with multiple knowledges, enacting this interaction through physical and digital spaces. There are, consequently, multiple points of reference in an information landscape, reflecting the complexity of people's interaction with extant information environments, and their associated knowledges and ways of knowing, hence the suggestion that information acts a cultural category.

In this conceptualisation, literacies of information (digital, visual, data, critical, health, etc.) represent expressions of information literacy practice; that is, they represent information literacy as it is practised in a setting. Information literacy is critical to the (re)building and (re)establishing of information landscapes and the practice is shaped by the modalities of information (social, physical and epistemic/instrumental), which represent the ways of knowing about the collective forms of knowledge that shape the larger information environment (Lloyd, 2006). These modalities are entwined, and the enactment of information literacy is predicated on the agreed-upon shared meanings about a project or collective endeavour and on the types of activity and action involved. People interact with multiple knowledges in their daily lives, played out through engagement with physical and digital spaces.

Successful resettlement and eventual integration are predicated upon access to a wide range of information environments (health, education, employment, etc.), leading to the construction of multiple landscapes to achieve the means and markers of integration (for example, find housing, gain employment, maintain health, participate in education and become a citizen) (Ager \& Strang 2008). 
These landscapes reflect the complex networks of people's interactions with analogue, digital, corporeal, and social information sources.

\subsection{Framing fractured landscape: Social theory and sensitising concepts}

The information perspective of fractured landscapes presented in this article is influenced by a suite of theories and sensitising concepts, particularly by the practice-theoretical approach of Schatzki (2002) and Theory of Practice Architectures (Kemmis \& Grootenboer, 2008; Mahon et al., 2017). In general, the practice-theoretical approach locates meaning in the enactment of social practices, including information practice such as information literacy, and in theories of social capital (Bourdieu, 1986; Putnam, 2000; Portes, 1998), which frame an account of people's use of information. The Theory of Practice Architectures describes how we encounter each other in practices.

\subsubsection{Practice theory}

Practice theory and practice-theoretical approaches are useful for understanding the fracturing and the project of remaking information landscapes. While the landscape of practice theory is varied, most accounts emphasise the "prioritisations of practices" (Schatzki, Knorr Cetina \& von Savigny, 2001, p. 11). These accounts are of the composition of practices and how they happen and are mediated and communicated in the constitution of social life. Social practices and their arrangements therefore become the starting point for theorising human affairs (Nicolini, 2012, p. 162; Schatzki, 2002), and, for the purposes of this article, aspects of resettlement into a third country as the result of forced migration.

In general, practice theorists are united in the rejection of dualism and advocate a refocused interest in the lifeworld, sharing a principle belief that practices are social and relational (Reckwitz, 2002, p. 244) and emphasising a re-centering of the body as a focus of attention. Theorists such as Reckwitz (2002) and Schatzki (2002) focus on the patterning of practices through suites of activities and shared understanding, while others attend to materials and materiality and the communication of practices through text and symbols. The breadth of scope in the practice landscape also suggests this field is unsettled (Feldman \& Orlikowski, 2011), primarily because accounts of practice are situated through a broad range of intellectual traditions (Nicolini, 2012).

Among the suite of practice theories, the Theory of Practice Architectures is of particular interest to this analysis (Kemmis \& Grootenboer, 2008). This theory provides an account of social reality that focuses on practices and how they are shaped, mediated, enabled and constrained through dimensions that make a practice hang together (Mahon et al., 2017). In general, the Theory of Practice Architectures posits that social life, and hence practice, is referenced through the cultural-discursive, material-economic and social-political dimensions that represent three kinds of arrangements that shape practice. In the context of the present discussion, a practice-theoretical approach enables us to conceptualise what fracturing might mean in terms of the loss of established epistemic, social or corporal information sources (Lloyd, 2006) and ways of knowing that are established over time and anchored in knowledges that shape the social and cultural elements of people being in the world.

\subsubsection{Social capital theory}

The arrangements made visible by a practice theory approach provide the resources required for building social capital. While social capital theory is often described in unproblematic terms, the potential exists to focus on power and the maintenance and privileging of knowledges by gatekeepers who valorise and favour certain points of view and knowledge and ways of knowing over others.

Bourdieu's (1986) interests in forms of capital rests in reproduction of society and maintenance of the status quo of stratification by the dominant and ruling classes. The concept of social capital highlights the inequality in social systems, focusing on how social classes strive to maintain resources, such as social connections and networks, which remain the privilege of a specific class to the exclusion of 
others. In the context of this discussion, refugees entering a host country may be subject to unequal access to the knowledges and narratives of a community and, by implication, to the modalities of information that shape the formation of information landscapes. From an information perspective, limited access to the social capital of a community represents barriers to information and knowledge and to the formal and informal means by which a person learns to become information literate and to apply literacies of information to become informed. This situation can lead to inequality and reduced capacity to "join in" and participate in the social, economic or political practices associated with citizenship of a community and larger society.

Other writers have advanced a less critical view of social capital, which, nonetheless, has an important contribution to make in understanding the kinds of "information work" that people who are new to a situation may need to do to transition, resettle and integrate into a new community. Putnam (2000, p. 19) defines social capital as "connections among individual's social networks and norms of reciprocity and trustworthiness that arise for them". Among the forms of social capital referenced by Putnam, "bonding capital" refers to the strong connections that create trust and reciprocity among people who share the same membership (such as familial, cultural, social, economic, or religious). Bonding capital denotes the willingness of people to represent and protect the interests and rights of members above all others. Emerging from bonding capital, however, is the role of gatekeepers and those with vested interests who have the capacity to restrict or direct the flow of information within a group. "Bridging capital" also emerges as an explanatory concept referencing the linking between people who are not connected by affiliation or membership and whose societal ties are weak. The benefits of bridging capital rest in greater access to broader networks (absence of vested interests).

\subsection{Sensitising concepts}

A range of sensitising concepts is also introduced in this discussion to deepen attention to the complexities of the fracturing and remaking of information landscapes.

\subsubsection{Affordances}

The concept of affordances (Gibson, 1979) describes the opportunities that are furnished by an information environment that enables interaction. Gibson's understanding of an affordance derives from the potential of an action or an object. The term has been extended by authors such as Norman (1988), who linked it to the properties of objects used in everyday life, producing a definition that suggests that affordances provide clues to potential use: "the term affordance refers to the perceived and actual properties of the thing, primarily those fundamental properties that determine just how the thing could possibly be used" (Norman, 1988, p. 9). Norman (1988, p. 123) also noted that the perceived affordances are what determine usability.

In relation to technology, and to social media in particular, affordances have been explored by boyd, who indicated that social network sites are shaped by four high-level affordances - persistence, replicability, scalability and searchability - which are central to the way in engagement is structured (boyd,2011, pp. 39-40). Schrock's research into mobile technology and affordances extends the concept by refocusing away from the "button" to identify portability, availability, locatability and multi-mediality (Schrock, 2015, p 1229) as central to the communicative practices and habits that enable or constrain these elements. Bucher and Helmond (2018, p. 13) suggest that, while most descriptions of affordances reference Gibson's original framing, they "differ in terms of where and when they see affordances materializing (i.e., features, artifacts, social structures) and what affordances are supposed to activate or limit (i.e., particular communicative practices, ...)". These authors also delineate between ontological and epistemological differences in how the concept is employed, citing the Gibsonian understanding as representing an ontological understanding, for example, the affordance is in the relation between a body and its environment, whereas an epistemological understanding is located in the technical features of a material objects (Bucher \& Helmond, 2018, p. 13). 
In the current analysis, affordances have a contextual dimension, but they are not a prerequisite for action unless they are meaningfully recognised by the participants as contributing to the remaking of fractured information landscapes (Lloyd, 2010, p. 167). Affordances can therefore be described as occurring in the relation between the body and its environment. Affordances are made available across the information modalities and expressed as: textual/instrumental (furnishing opportunities to connect with codified knowledges); social (furnishing interactional opportunities between people); or physical and linked to materials or embodied knowledges located within the physical environment (Lloyd, 2010). The relationship between affordances and information has to be understood as meaningful and useful to a particular practice or activity (Chemero, 2003). For affordances to be taken up by an individual, they must be perceived as an opportunity, which suggests that the value of the affordance (a resource, a tool, a person, or piece of information) must be recognised by the individual (Lloyd 2010) in the site of the practice.

\subsubsection{Temporal intensification}

The enmeshment of internet and digital culture into the daily lives and everyday transactions of people has been viewed by numerous scholars as creating a perception of acceleration in society (Rosa, 2013; Wajcman \& Dodd, 2017). Emerging from the present analysis is the conception of temporal intensification, as a product of this acceleration. When discussed in relation to technology acceleration, this references the perception that time moves at an accelerated pace largely because of technological influences and practices (Wajcman \& Dodd, 2017). The concept of temporal intensification and acceleration have implications for refugees who are rebuilding their fractured information landscapes.

Information landscapes are not static, but dynamic and always evolving relative to the complexity of the lived experience. Landscapes and practices are constructed against and through a background of time, space and against conditions such as acceleration. Consequently, information landscapes reflect the practices of a particular site and are subject to the phenomenon of time and speed. Time "is a social entity, formed through collective rhythms of human engagement with the world" (Wajcman \& Dodd, 2017 , p. 2). Intensification of an information landscape represents the altered flow of socio-cultural and socio-material practices as a consequence of technological acceleration. An outcome of the present intensification period is time consciousness, brought about by temporality being experienced in multiple ways, across many platforms, and via multiple modalities (Wajcman \& Dodd, 2017). In short, modern society appears to be faster because digital culture no longer stands adjacent to entrenched cultural notions, but is enmeshed within them.

Refugees may experience temporal intensification as they move from global south locations to receiving countries that may be categorised as the global north, the implication being that global north countries generally have better technological infrastructure, including greater interconnectivity and faster response speeds, which create the conditions for higher input and output of information. This may lead to information overload, source uncertainty, or precarity.

\section{What does forced migration do? Fractured information landscapes}

From an information perspective, the concept of fracture can be used to explain the impact of forced migration on the established knowledge bases and ways of knowing of people who are forced to leave their home countries because it is no longer safe for them to remain. The fracturing of their landscape places people in a position of reconciling established knowledges with those of the new settings or contexts they are entering (Lloyd, Lipu \& Kennan, 2010; Lloyd, 2015).

To sketch the analytical contours of the impact of fracture, three themes (intensification, disjuncture and liminality) which have emerged across the studies undertaken by the author and her colleagues are introduced. Implicated throughout the present analysis is a conceptualisation of information as a 
cultural category, which references the sayings, doings, and relatings that anchor people and practices to a setting and provide the informing quality of inherent intersubjective meanings and understandings that are evident within a setting.

\subsection{Fracture}

Describing landscapes as fractured creates an entry point for analysis of what enables or constrains information practices and leads to the construction of knowledge and ways of knowing in a strange land (Lloyd, 2015). The fracturing of information landscapes represents the fragmentation of socialdiscursive, material-economic and social-political arrangements and disrupts access to epistemic, social, embodied, and nuanced information and ways of knowing (Lloyd, 2017). There is evidence of the fracture of landscapes in the voices of refugee participants quoted in the following section.

\subsection{Intensification (too much information and too little time)}

The fracturing of information landscapes has temporal and spatial elements representing a loss or diminution of embodied knowledges and ways of knowing. Across the studies by the author and her colleagues, the concept of fracture is referenced through narratives about the acceleration of time. Disconnection from the old and reconnection to a range of information environments in receiving countries are underscored by uncertainty and the urgency to become re-established. For most participants, the project of resettlement is marked by the necessity to recognise the social, material, and technological affordances furnished by the new setting that willscaffold their capacity to redevelop their information landscapes.

The resettlement processes and experiences studied by the author and her colleagues to date have unfolded within societies experiencing technological acceleration and intensification (that is, within Australian and Swedish societies). The rate of information dissemination (from governments, NGOs and social media sources), the range of tools for dissemination, and the capacity to access information from ever-widening fields contribute to narratives of accelerated time and an overall feeling of intensification. Intensification creates the conditions for precarity and pushes against people's capacity to develop information resilience.

A participant in the Settlers Study (Lloyd, et, al 2013) described the overwhelming amount of information that is provided and the impact of acceleration on individual agency:

It's huge, I guess it's all come down to time - like as a community [name removed] haven't got

time to wait for people like me, for example if you give me ... this one [referring to an application form and information sheet] it will take me about 3 or 4 hours to read it and I don't know what the content is but in ... we just look at it came through in 5 minutes it's all over what is it ... and here are people coming from outside who have got nothing to do and they will have to study ... and by the time they arrive here within a fortnight a letter from [government organisation] you need to do this you need to do that,... devastating.

As refugees connect with societies that have more developed digital infrastructures and systems, that are often faster, more information rich, and more complex than their own established experiences, they experience a sense of time impoverishment and, often, pressure because of the rapid dissemination of information. This often results in information overload, or a sense of precarity that may arise when previous stable sources of knowledge are no longer available. An outcome of the increasing tendency of governments, NGOs, and third sector agencies to provide information to refugees online is the acceleration of objective time/space. As a consequence of this acceleration, refugees position themselves to meet the demands of highly connected societies by learning to recognise the affordances furnished by the new information environments and draw from these to rebuild their information landscapes. In addition, acceleration may create information overload as refugees work to reduce the 
"noise" of a host country in order to rebuild their landscapes. A temporal element is also present in the rebuilding of information landscapes, because ways of knowing the nature and nuances of language, and thus communication, change. People need time to be able to interpret and reconstruct meaning, and to reconcile this with their ways of knowing.

\subsection{Disjuncture}

Fracturing has the capacity to create a sense of disjuncture, described here as separation or disconnection from established information landscapes that reference the familiar information environment of past life. A participant in the SpiRiT Study (Lloyd, Pilerot \& Hultgren, 2017) described disjuncture in the following way: "When you come into the society you need to be like them. If you do make a mistake all of the attention will be with you, what you did that."

Where people become disconnected or separated from contexts and reference points (e.g. health, welfare, education, normative rules, communal intersubjectivity, and embodied ways of knowing) that are historically linked to their established communities, institutions, organisations and practices, their new experiences may be underscored by uncertainty about the efficacy of information Lloyd 2017, p. 40), or insecurity about access which can lead to a situation of precarity and diminished capacity for resilience. A participant from the SpiRiT Study, expressed this uncertainty in the following way: "She is speaking about how unsettled she feels because she can't continue her education and she doesn't know anything about what will happen with her children."

Forced migration creates disjuncture by separating people from common information sources derived through language, from close familial and social ties, and from cultural and social events. Disjuncture is also referenced in the lived experience of refugees by the difficulty many people experience in connecting and understanding institutional information of the receiving country and reconciling established ways of knowing with those of their receiving country. A participant in the Settlers Study expressed this difficulty: "It took me a time to understand what [government organisation] was all about.".

\subsection{Liminality}

The fracturing of information landscapes has the capacity to contribute to a sense of liminality, that is, of being in a state of disconnection between spaces, or located betwixt and between (Turner, 1967). Liminality or being cast to the margins was a common theme in the studies by the author and her colleagues. A participant in the Health Study (Lloyd 2015) described it as being in the "middle of nowhere":

The thing is when people arrive, there's a lot to learn, you know, you come to a country where you don't know anybody or anything, so it is like you are put in the middle of nowhere you see, our people-we ... here like we're in the middle of nowhere but there's a lot of people around rou, but you still find yourself in the middle of nowhere.

For refugees across the studies, liminality is referenced in the space that exists between a functioning society and its margins (Lloyd, 2015). Conditions of intensification and disjuncture have the capacity to push people out to the margins of society. The state of liminality represents the inability of people to push into the mainstream of a receiving society in order to access the affordances embedded in the cultural-discursive space that provides the discursive directions for social engagement; the socialpolitical space, where resources (information) that relate to power and solidarity are located through the nuanced activities of alignment and membership (Lloyd, 2010); and the material-economic arrangements that afford opportunities to understand how things happen.

\section{Shaping the contours of fracture}


In the studies (see section 1.2 above) that inform the analytical concept of fracture, resettling into a third country is predicated upon the assignation of refugee status and with that the assumption of there being be no possibility to return to the homelands from which they fled. Resettlement in a third country is a complex experience of remaking and re-establishing social networks. It is marked by the need to access new information relating to the social, cultural, economic and political conditions of a new context, and to develop new information practices that enable access to information resources of that new setting - needs that shape and influence the lived experience of resettling refugees. Refugees in this situation may experience overload, which may lead to situations in which they experience liminality (Turner, 1967) or become marginalised and socially excluded because they cannot decipher and learn how the host society functions and the rules and conventions by which it operates.

Resettlement is not solely about transitioning and possibly integrating into a new country; it is also intrinsically connected with issues of reclaiming identity, repairing disrupted lives, and belonging (Díaz Andrade \& Doolin 2019).

In the process of resettlement, refugees need to reconcile their previous information landscapes and ways of knowing about how things operate and happen with those of the country they resettle in. Refugees whose experience is reported in the studies noted in section 1.2 describe this as a cyclical and iterative process of orientation and reorientation, underpinned by learning and developing information practices that enabled them to access, connect, and engage with information sources about how their host countries operate. For example, they needed to learn the formal explicit rules guiding the practice and conduct of citizenship in a new country, to deal with compliance issues related to their asylum or refugee designation, to learn about forms of education, health and activities associated with ensuring their well-being, and opportunities for training and employment. At more informal or local levels people must connect with information that allows them to go on in community, which means accessing local knowledges and ways of knowing that are not explicit or written down.

Being introduced to new information environments influences the way in which people's information landscapes are reshaped. When entering and engaging with a new community, new members learn to map the information sources necessary for their everyday practices. They learn about the material, economic, political and historical resources that shape the site of the social (Schatzki, 2002; Lloyd, 2010) and the range of information practices that will facilitate access to social and embodied knowledges of the practice. As they learn about these social, embodied and epistemic sources, they construct their information landscapes and define paths, nodes and edges with reference to the larger information environment. Kearning about which information practices enable access to knowledge is integral to the formation of information landscapes, such as information sharing, observing others and their environments, and being reflexive.

By combining an information perspective with a practice-theoretical approach (Kemmis \& Grootenboer, 2008; Mahon et al., 2017), researchers are able to analyse the resettlement experience of refugees and focus on how the cultural-discursive, material-economic and social-political dimensions that Shape the discursive practices of people engaged in a particular project or setting become fractured and fragmented in the act of forced migration. To elaborate, a practice-theoretical perspective focuses attention on the:

- Cultural-discursive dimension - a semantic space where people meet each other and the discursive practices of a setting through language, that is, what is sanctioned as legitimate in terms of what can be said (sayings) about information or what types of knowledge are important, and what activities are legitimate and agreed upon within group, organisation or collective. The semantic space references the epistemic modality where information is explicit, objective and reproducible (Lloyd, 2012). Forced migration and resettlement has the potential to fracture the stability of this dimension and requires refugees resettling in a new country to connect with situated knowledges that enable them to become informed about the information 
practices and behaviours that will provide access to formal knowledges, such as policies, rules and regulations that control and prescribe their resettlement process.

- Material-economic arrangements - the conditions that enable or constrain the way things happen in a specific setting or practice (doings), such as the way in which information is circulated within a community or setting, the way in which it is navigated and then accessed via technology and through online or face-to-face communication, or through observing others as they participate in the practices that shape everyday life. The material-economic space reflects embodied and nuanced ways of knowing that are central to the everyday performances of an individual or group and is referenced through the corporeal modality. Forced migration fractures this space by disrupting access to and flow of information, routes and practices of navigation that people establish over time.

- Social-political dimension - arrangements of the social space relating to solidarity and power, such as life world processes, the development of shared meanings, and practical arrangements. For refugees, learning the practice of information literacy enables them to tap into resources that are often nuanced and may be difficult to express in written form. Activities often focus on the sharing of information that is important in negotiation, participation, and membership. Forced migration fragments communities and their shared ways of knowing. It creates conditions in which people experience intensification, disjuncture and a sense of liminality because their connection to the cultural-discursive, material-economic and social-political dimensions that shape their practices, including their information practices, is disrupted.

Applying this conceptualisation to refugee resettlement practices brings into focus how people learn to go on in a setting by identifying the sayings, doings and relatings that shape the intersubjective spaces represented by the cultural-discursive, material-economic and social-political dimensions.

\section{The project of remaking and the role of technology}

In the project of remaking, participants turn towards their receiving societies by reorienting themselves through a process of identifying the range of affordances that could fill in information gaps, rebuild their social capital, adjust and modify their established ways of seeking information and of knowing to accommodate the disruption. By reorienting themselves they are able to reframe and reconstruct information landscapes to accommodate new content and competency knowledge within their new environments. This process has been described as cyclical and iterative (Kennan et al., 2011).

Reconstructing a fractured landscape requires people to engage with information work to scaffold their capacity to understand how the social environments of their receiving community are constituted. They need to understand what constitutes information; what information and knowledges are valued; how to determine sources that will support resettlement by creating the conditions for integration to happen; how information is produced, reproduced, circulated and made accessible; what and whose information can be trusted; and, how to evaluate credibility. The tricky and complex process of remaking is predicated upon refugees' capacity and ability to:

recognise, locate and connect to information affordances that express the collective rhythms of a receiving society and reconciling these affordances with their established ways of knowing (Lloyd, Lipu \& Kennan, 2010);

- make and remake social networks, and develop bonding and bridging capital (Putnam, 2000) which permit newcomers to connect with discourses about citizenship, language and culture (Strang \& Ager, 2010), while simultaneously maintaining important cultural and familial connections (Lloyd, 2016)

- successfully navigate the digital world to meet the markers of integration, by gaining the ability to develop information practices that enable access to information about employment, education, housing, health care (Ager \& Strang, 2008; Lloyd, 2014) and everyday life. This also involves developing information and digital literacy skills and using ICTs to respond to their changed circumstances, while at the same time regaining and maintaining social and cultural 
connections anchored in their previous lives that may be become disrupted during transition and resettlement.

\section{How is technology implicated in the remaking of place?}

The conceptualisation of a fractured landscape is framed against a period in time that could be characterised as technologically intensive and pervasive. Against this view the project of remaking is enmeshed and enacted in a world where access and ways of knowing are increasingly shaped by technologies and systems and influenced by algorithmic cultures (Seyfert and Roberge, 2016) that increasingly influence how culture is practised, experienced and understood (Striphas, 2015, p.395).

For refugees, who often demonstrate high connectivity, these socio-technical and material enmeshments have both positive and negative affordances, which enable and constrain transition, resettlement, and the potential for integration. On one hand, digital technologies can enable reconnection and help to build social relations within receiving communities, while also maintaining social connections and creating an ambient co-presence with families and communities Reft behind (Madianou, 2016). In the context of this conceptualisation, “.... affordances are not understood as being experienced in isolation, but rather in relation to a complex ecology of other tools with other affordances" (McVeigh-Schultz, \& Baym 2015, p. 2). While this makes the study of affordances (and their discussion) as bounded objects tricky, an alternative approach is to view affordances as opportunities that enable and/or constrain. In this analysis affordances enable and constrain at functional, emotional, social and instrumental levels. On the other hand, ubiquitous technologies must also be viewed as disruptive of long-term relations, given the difficulty of navigating national systems and the capacity for online applications to be used for surveillance, which can be counterproductive to the project of remaking.

\subsection{Enablement}

Across the studies undertaken to date, it has been found that ubiquitous technology such as smartphones, online platforms, and social media applications play a functional and relational role in the remaking of place. At a relational leyel, mobile phones and social media platforms afford opportunities for communicative practices that can address disjuncture or liminality. This is facilitated through the establishment of new social networks, which facilitate bridging capital and establish the new paths, nodes and edges for the information landscapes that are essential for successful integration.

Technology and the proliferation of online platforms available are also a factor in building capacity to address the narratives of disjuncture and enable the reconstruction of information landscapes because they afford opportunities for exploring new information environments and mapping the paths, nodes and edges that establish them. In many interviews across the studies undertaken by the author and her colleagues, participants' had their mobile phones with them and often used them to demonstrate the social media, online apps, and websites they considered important. In the KaLieds project (Lloyd \& Wilkinson, 2019), which employed photovoice methods, refugee youth took photos of their phones, computers and apps as representing important sources of information. The project identified mobile phones as enablers with the capacity to afford participants opportunities to rebuild fractured landscapes by reconnecting and linking to their past lives, mediating their current lives, and affording opportunities to connect to information that would help them plan for their future lives.

Technology was also found to play a confirmational role, as it afforded opportunities for participants to check and confirm the veracity of information from multiple sources. While other people are central to the verification process, trust in socially delivered information is reinforced by checking and confirming online (Lloyd, 2014). In the SpiRiT Study (Lloyd, Pilerot \& Hultgren, 2017), participants identified and described the role of the Swedish migration office (Migratationsverket) and its online 
presence as a significant and trusted repository of institutional information essential to rebuilding their lives.

Affordances are also furnished by technology in opportunities to reconnect with family and develop a functioning sense of co-presence. Social media spaces enable connection with others sharing the same experiences. They also scaffold the ambient co-presence (Madianou, 2016) necessary to maintain familial links with family and friends overseas through discussion of everyday activities and events.

Participants described the creation of co-presence in the following ways: we talk about their daily routines, their work ... it seems that the world is very small (SpiRiT Study)

Facebook really can keep you connected with what's going on in your families at home and it keeps them connected with you as well (KaLieds study)

I have connection with my friend in Syria and I have connection with my family. That always comes about Facebook in the first because when I do anything, we can say, when I bring driver licence I take a picture and I put it in the Facebook. All my friends talk about what happened with me, the same for me with them, if they say (SpIRiT Study)

\subsection{Constraints}

While technology plays an enabling role, it can also impose constraints that keep people on the margins of a receiving society by creating conditions for inequality, particularly in relation to digital landscapes and access to information. Technology can also slow down integration by creating virtual communities or bubbles that reflect a refugee's country of origin. In another study (Wall, Otis Campbell \& Janbek, 2017), mobile phones and online applications were also viewed as creating potential conditions for surveillance, thus adding another layer of complexity to the integration process of those refugees using such technologies.

Internet culture and the enmeshment of technology into everyday life has altered perceptions of time and speed, which may inhibit successful connection with the receiving countries and the remaking necessary for building information resilience (Lloyd, 2015) and approaching social inclusion. Across all the studies conducted by the author and her colleagues, participants identified the speed of information delivery and the complexity of digital landscapes as often creating barriers. Speed, coupled with the less proficient language skills, can result in a situation where refugees become uncertain about information required and where it is located, so that they require more time to work through information and provide appropriate responses. This can lead to fear of not complying with requirements within specified periods, because it takes longer to process and understand information relevant to compliance.. As a SpiRiT Study participant expressed it:

They need to know what they need to do and everything about their settlement process before the two years end. They are always in fear and asking questions before these two years expire. What anyone needs to know as a refugee is someone who can direct them into the right places togo, things they need to know.

An additional factor is a receiving society's failure to understand the implications of the algorithmic culture that is infused in online life and the impacts on refugee transition, resettlement, and integration decisions of treating refugees as a specific class with similar needs. In the SpiRiT Study, online sites were viewed by participation as sources of push information and as places to upload required forms and to receive decisions. The decision route related to refugees being able to undertake language courses necessary to transition into work was a case of concern for Syrian refugees (most of whom had tertiary degrees: "they are doctors, engineers, .... and they used to get general information, what they need is personalised information" (translation from SpiRiT Study interview)). Regardless of educational level, refugees in Sweden are required to follow a specific route designated within the system. Another participant in the SpiRiT Study indicated that he preferred to visit the government 
offices and talk to face-to-face because he could "get better information...(and was) more specialised" to his need.

The need for specialised information highlights that, while the designation "refugee" categorises and politicises a specific class of people, it is important to that people's resettlement experiences and their need for information are recognised to vary. This recognition can lead to challenges in developing information and delivering it online to refugees as a "category of people".

Dourish (2016) and Burrell (2016) highlight the social and cultural implications of machine learning in terms of the capacity of algorithms to shape information flow and access to forms of social media, to influence the distribution of search results, to provide recommendations that shape people's relationships and performances. According to Burrell (2016), while machine learning may identify interesting patterns of interaction, it is not able to make sense of these patterns. Algorithmic culture therefore has implications for refugees, who largely rely on forms of online media for information but may lack the range of literacy and literacies of information required for understanding the veracity of that information and how to gain access to it, which algorithmic culture fails to accommodate.

\section{Conclusion}

This article has aimed to extend the layering of an information perspective to the practice of resettlement which results for some refugees from forced migration. When viewed from this perspective, forced migration and resettlement can be problematised against concepts of information landscapes, literacies, information resilience, and affordances, with practice theory and social capital theory providing explanatory frameworks.

Forced migration creates complex social, cultural and political information problems for people by fracturing established information landscapes that have been created and anchored in previous lives and reflected in lived experiences of social networks. Knowing what is needed, where and when it is needed, how to acquire and access information, and what or whom to trust is predicated upon understanding what information is important in a cultural context and then reconciling that knowledge with an internal understanding of what constitutes information and knowledge. This form of knowing is set against the challenges of temporal acceleration, created by increased use of technologies, and a greater reliance on the internet and social media platforms to function as the main source of information dissemination for refugees. While they are heavy users of technology, refugees often lack the information and digital literacy skills to competently navigate and understand the veracity of internet resources and often feel pressured to respond to institutional requests relevant to their residency. This raises questions about how to assist refugees in meeting the challenges of remaking information landscapes, particularly in societies accelerated by technologies and where agency increasingly being influenced and shaped by alogrithms.

Exploring forced migration and the information experience of refugees opens an interesting avenue of enquiry that requires researchers to take a problematised view of information practices, information seeking and use in the context of displacement. It also affords an opportunity to investigate how information landscapes that have become fractured are re(constructed).

\section{REFERENCES}

Audunson R, Essmat S and Aabø S (2011), "Public libraries: A meeting place for immigrant women?", Library \& Information Science Research, Vol.33 No 3, pp: 220-227 Ager, A., \& Strang, A. (2008). Understanding integration: A conceptual framework. Journal of Refugee Studies, 21(2), 166-191.

Alencar, A., (2018) Refugee integration and social media: a local and experiential perspective,Information, Communication \& Society, 21:11, 1588-1603. 
Allard, D., \& Caidi, N. (2018). Imagining Winnipeg: The translocal meaning making of Filipino migrants to Canada. Journal of the Association for Information Science and Technology, 69(10), 1193 1204.

Allard, S., Mehra, B., \& Qayyum, M. A. (2007). Intercultural leadership toolkit for librarians: Building awareness to effectively serve diverse multicultural populations. Education Libraries, 30(1), 5-12.

Appadurai, A. (1996). Modernity at large: Cultural dimensions of globalization. Minneapolis: University of Minnesota Press.

Banki, S. (2013). Precarity of place: A complement to the growing precariat literature. Global Discourse, 3(3-4), 450-463.

Barad, K. (2007).Meeting the universe halfway: Quantum physics and the entanglement of matter and meaning. Durham, NC: Duke University Press.

Bates, M. J. (1999). The invisible substrate of information science. Journal of the American Society for Information Science, 50(12), 1043-1050.

Bourdieu, P. (1986/2011). The forms of capital (1986). In I. Szeman \& T. Kaposy (Eds.), Cultural theory: An anthology (pp. 81-93). Chichester: Wiley-Blackwell.

boyd, d. (2011). Social networking sites as networked publics: Affordances, dynamics, implications. In Z. Papacharissi (Ed.), A networked self (pp. 39-58). New York: Routledge.

Bucher, T., \& Helmond, A. (2018). The affordances of social media platforms. In J. Burgess, A. Marwick, \& T. Poell (Eds.), The SAGE handbook of social media (pp. 223-253). London: Sage. Buckland, M. K. (1991). Information as thing. Journal of the American Society for Information Science, 42(5), 351-360.

Burrell, J. (2016). How the machine 'thinks': Understanding opacity in machine learning algorithms. Big Data \& Society, 3(1), 1-12.

Butler, J. (2006). Precarious life: The powers of mourning and violence. London: Verso.

Caidi, N and Allard, D (2005), "Social inclusion of newcomers to Canada: An information problem? Library \& Information Science Research”, Vol. 27 No.3,pp. 302-324.

Castles, S, \& Miller, M (2009) The age of migration: International population movements in the modern world ( $4^{\text {th }}$ Ed.), Guildford Press, London.

Dali, K. (2010). The Psychosocial Portrait of Immigration through the Medium of Reading: Leisure Reading and Its Role in the Lives of Russian-Speaking Immigrants in Toronto ,Doctoral dissertation, University of Toronto.

Dekker, R., Engbersen, G., Klaver, J., \& Vonk, H. (2018). Smart refugees: How Syrian asylum migrants use social media information in migration decision-making. Social Media + Society, 4(1), 111.

Díaz Andrade, A., \& Doolin, B. (2019). Temporal enactment of resettled refugees’ ICT-mediated information practices. Information Systems Journal, 29(1), 145-174.

Dourish, P. (2016). Algorithms and their others: Algorithmic culture in context. Big Data \& Society, $3(2), 1-11$.

Dourish, P. B., \& Bell, G. (2011). Divining a digital future: Mess and mythology in ubiquitous computing. Cambridge, MA: MIT Press.

Dourish, P. B., Brewer, J., \& Bell, G. (2005). Information as a cultural category. Interactions, 12(4). Fisher, K., Durrance, J. C., \& Bouch Hinton, M. (2004), ' Information grounds and the use of needbased services by immigrants in Queens, New York: A context-based, outcome evaluation approach", Journal of the American Society for Information Science and Technology, Vol.55 No 8,pp. 754-766 Feldman, M. S., \& Orlikowski, W. J. (2011). Theorizing practice and practicing theory. Organization Science, 22(5), 1240-1253.

Fisher, K (2018) Information Worlds of Refugees, in Maitland, C., Braman, S., \& Jaeger, P. T (eds.), Digital Lifeline?: ICTs for Refugees and Displaced Persons. The MIT Press, pp 79-112

Fisher, K. E., Yefimova, K., \& Yafi, E. (2016, June). Future's Butterflies: Co-Designing ICT

Wayfaring Technology with Refugee Syrian Youth. In Proceedings of the The 15th International Conference on Interaction Design and Children(pp. 25-36). ACM. 
Fisher, K. E., Talhouk, R., Yefimova, K., Al-Shahrabi, D., Yafi, E., Ewald, S., \& Comber, R. (2017). Za'atari refugee cookbook: Relevance, challenges and design considerations. In Proceedings of the 2017 CHI Conference Extended Abstracts on Human Factors in Computing Systems (pp. 2576-2583). New York: ACM.

Furner, J. (2015). Information science is neither. Library Trends, 63(3), 362-377.

Geertz, C. (1994). Thick description: Toward an interpretive theory of culture. In M. Martin \& L. C. McIntyre (Eds.), Readings in the philosophy of social science (pp. 213-232). Cambridge, MA: MIT Press.

Gibson, J. J. (1979). The theory of affordances. Chapter 8 of his The ecological approach to visual perception (pp; 127-143). Boston: Houghton Mifflin.

Gillespie, M., Ampofo, L., Cheesman, M., Faith, B., Iliadou, E., Issa, A.,\& Skleparis, D. (2016).

Mapping refugee media journeys.Smartphones and Social Media Networks. The Open

University/France Médias Monde (Research Report) accessed March

2017 `https://www.open.ac.uk/ccig/sites/www.open.ac.uk.ccig/files/Mapping\%20Refugee\%20Media\% 20Journeys\%2016\%20May\%20FIN\%20MG_0.pdf

Gillespie, M., Osseiran, S., \& Cheesman, M. (2018). Syrian refugees and the digital passage to Europe: Smartphone infrastructures and affordances.Social Media+ Society,4(1), pp1-12.

Gilhooly, D., \& Lee, E. (2014). The role of digital literacy practices on refugee resettlement: The case of three Karen brothers. Journal of Adolescent \& Adult Literacy, 57(5), 387-396.

Kemmis, S., \& Grootenboer, P. (2008). Situating praxis in practice: Practice architectures and the cultural social and material conditions for practice. In S. Kemmis \& T. Smith (Eds.), Enabling praxis: Challenges for education, pp.37-62. Rotterdam: Sense.<smiles>C1CCC1</smiles>

Kennan, M. A., Lloyd, A., Qayyum, A., \& Thompson, K. (2011). Settling in: The relationship between information and social inclusion. Australian Academic \& Research Libraries, 42(3), 191-210.

Khoir, S., Du, J. T., \& Koronios, A. (2015). Linking information behaviour and everyday experiences to immigrant settlement processes: Towards a conceptual framework. Australian Academic \& Research Libraries, 46(2), 86-100.

King, R (2013) Theories and typologies of migration: An overview and a primer, Righard, R (Ed.), Wily Brandt Series of Working Papers in International Migration and Ethnic Relations 3/12. Malmo Institute for Studies of Migration, Diversity and Welfare (MIM), Malmo, Sweden.

Komito,L.(2011).Social media and migration: Virtual community 2.0.Journal of the American Society for Information Science and Technology, 62,1075-1086.

Le Louvier, K., \& Innocenti, P. (2019). The information mapping board game: A collaborative investigation of asylum seekers and refugees' information practices in England, UK. Information Research, 24(1). http://www.informationr.net/ir/24-1/isic2018/isic1835.html Accessed 24 April 2019. Lloyd, A. (2006). Information literacy landscapes: An emerging picture. Journal of Documentation, 62(5), 570-583.

Lloyd, A. (2010). Information literacy landscapes: Information literacy in education, workplace and everyday contexts. Oxford: Chandos.

Lloyd, A. (2014). Building information resilience: How do resettling refugees connect with health information in regional landscapes: Implications for health literacy. Australian Academic \& Research Libraries 45(1), 48-66.

Lloyd, A. (2015). Stranger in a strange land: Enabling information resilience in resettlement landscapes.Journal of Documentation,71(5), 1029-1042.

Lloyd, A. (2017). Researching fractured (information) landscapes: Implications for library and information science researchers undertaking research with refugees and forced migration studies. Journal of Documentation, 73(1), 35-47.

Lloyd, A., Kennan, M. A., Thompson, K. M., and Qayyum, A. (2013). Connecting with new information landscapes: Information literacy practices of refugees. Journal of Documentation, 69(1), 121-144.

Lloyd, A., Lipu, S., \& Kennan, M. A. (2010). On becoming citizens: Examining social inclusion from an information perspective.Australian Academic \& Research Libraries, 47(4), 304-315. 
Lloyd, A., Pilerot, O. \& Hultgren, F. (2017). The remaking of fractured landscapes: Supporting refugees in transition (SpiRiT). Information Research, 22(3), paper 764. Retrieved from http://InformationR.net/ir/21-1/paper764.html (Archived by WebCite ${ }^{\circledR}$ at http://www.webcitation.org/6tTRmq2S2)

Lloyd, A., \& Wilkinson, J. (2019). Tapping into the information landscape: Refugee youth enactment of information literacy in everyday spaces. Journal of Librarianship and Information Science, 51(1), 252-259.

Madianou, M. (2016). Ambient co-presence: Transnational family practices in polymedia environments. Global Networks, 16(2), 183-201.

Mahon, K., Kemmis, S., Francisco, S., \& Lloyd, A. (2017). Introduction: Practice theory and the theory of practice architectures. In K. Mahon, S. Francisco, \& S. Kemmis (Eds.), Exploring education and professional practice (pp. 1-30). Singapore: Springer.

Maitland, C., Tomaszewski, B., Belding, E., Fisher, K., Xu, Y., Iland, D.,\& Majid, A. (2015). Youth mobile phone and internet use January 2015 Za'atari camp, Mafraq, Jordan.Penn State College of Information Sciences and Technology.accessed October 2017 accessed October 2017 https://www.cs.princeton.edu/ pschmitt/docs/zaatari_tech.pdf .

Martzoukou, K., \& Burnett, S. (2018). Exploring the everyday life information needs and the sociocultural adaptation barriers of Syrian refugees in Scotland. Journal of Documentation, 74(5), 11041132.

McVeigh-Schultz, J., \& Baym, N. K. (2015). Thinking of you: Vernacular affordance in the context of the microsocial relationship app, Couple. Social Media + Society, 1(2), 1-13.

Nicolini, D. (2012). Practice theory, work, and organization: An introduction. Oxford: Oxford

University Press.

Norman, D. A. (1988). The psychology of everyday things. New York: Basic Books.

Oduntan, O., \& Ruthven, I. (2019). The Information Needs Matrix: A navigational guide for refugee integration. Information Processing \& Management, 56(3), 791-808.

Portes, A. (1998). Social capital: Its origins and applications in modern sociology. Annual Review of Sociology, 24(1), 1-24.

Putnam, R. D. (2000). Bowling alone: America's declining social capital. In L. Crothers, \& C. Lockhart (Eds.), Culture and politics (pp. 223-234). New York: Palgrave Macmillan.

Quirke, L. C. (2014), A study of the information practices of Afghan newcomer youth in the contexts of leisure and settlement (Doctoral dissertation, University of Toronto).

Reckwitz, A. (2002). Toward a theory of social practices: A development in culturalist theorizing.

European Journal of Social Theory, 5(2), 243-263.

Rosa, H. (2013). Social acceleration: A new theory of modernity. New York: Columbia University Press.

Schatzki, T. R., Knorr Cetina, K., \& von Savigny, E. (Eds) (2001). The practice turn in contemporary theory. London: Routledge.

Schatzki, T. R. (2002). The site of the social: A philosophical account of the constitution of social life and change. University Park, PA: Pennsylvania State University Press.

Schrock, A. R. (2015). Communicative affordances of mobile media: Portability, availability, locatability, and multimediality. International Journal of Communication, 9.

Seyfert, R., \& Roberge, J. (Eds.). (2016). Algorithmic cultures: Essays on meaning, performance and new technologies. Abingdon: Routledge.

Srinivasan, R., \& Pyati, A. (2007). Diasporic information environments: Reframing immigrant-focused information research.Journal of the American Society for Information Science and Technology, 58(12), 1734-1744.

Strang, A., \& Ager, A. (2010). Refugee integration: Emerging trends and remaining agendas. Journal of Refugee Studies 23(4), 589-607.

Striphas, T. (2015). Algorithmic culture. European Journal of Cultural Studies, 18(4-5), 395-412. Turner, V., (1967). Betwixt and between: The liminal period in Rites de Passage. Chapter 4 The forest of symbols: Aspects of Ndembu ritual. Ithaca, NY: Cornell University Press.

United Nations High Commissioner for Refugees (2012) The State of the World's Refugees; A humanitarian Agenda, Oxford, Oxford University Press 
United Nations High Commissioner for Refugees (2002) NHCR. Refugee resettlement: An international handbook to guide to reception and integration. (2002).

https://www.unhcr.org/uk/protection/resettlement/4a2cfe336/refugee-resettlement-internationalhandbook-guide-reception-integration.html Accessed 24 April 2019

United Nations High Commission for Refugees (2011) Resettlement Handbook. United Nationsl Commioner for Refugees; Geneva: Switzerland. Accessed April 24, 2019

https://www.unhcr.org/uk/protection/resettlement/4a2ccf4c6/unhcr-resettlement-handbook-countrychapters.html

United Nations High Commission for Refugees (2016) UNHCR Viewpoint: 'Refugee' or "migrant"Which is right? Accessed 2017 https://www.unhcr.org/uk/news/latest/2016/7/55df0e556/unhcrviewpoint-refugee-migrant-right.html UNHCR. The global compact on refugees: Final draft (as at 26 June 2018). (2018). https://www.unhcr.org/5b3295167 Accessed 24 April 2019.

Van Hear, N. (2012), Forcing the Issue: Migration Crises and the Uneasy Dialogue between Refugee Research and Policy. Journal of Refugee Studies, 25(1), 2-24

Vårheim, A. (2014). Trust and the role of the public library in the integration of refugees: The case of a northern Norwegian city. Journal of Librarianship and Information Science, 46(1), 62-69.

Wajcman, J., \& Dodd, N. (Eds.). (2017). The sociology of speed: Digital, organizational, and social temporalities. Oxford: Oxford University Press.

Wall, M., Otis Campbell, M., \& Janbek, D. (2017). Syrian refugees and information precarity. New Media \& Society, 19(2), 240-254.

Yu, L. (2010) How poor informationally are the information poor?: Evidence from an empirical study of daily and regular information practices of individuals. Journal of Documentation, Vol. 66 No. 6, pp. 906- 933.

\section{Competing Interest Statement}

The author has not competing interests to declare. 